Cochrane Database of Systematic Reviews

\title{
Endonasal versus external dacryocystorhinostomy for nasolacrimal duct obstruction (Review)
}

Jawaheer L, MacEwen CJ, Anijeet D

Jawaheer L, MacEwen CJ, Anijeet D.

Endonasal versus external dacryocystorhinostomy for nasolacrimal duct obstruction.

Cochrane Database of Systematic Reviews 2017, Issue 2. Art. No.: CD007097.

DOI: 10.1002/14651858.CD007097.pub3.

www.cochranelibrary.com 
TABLE OF CONTENTS

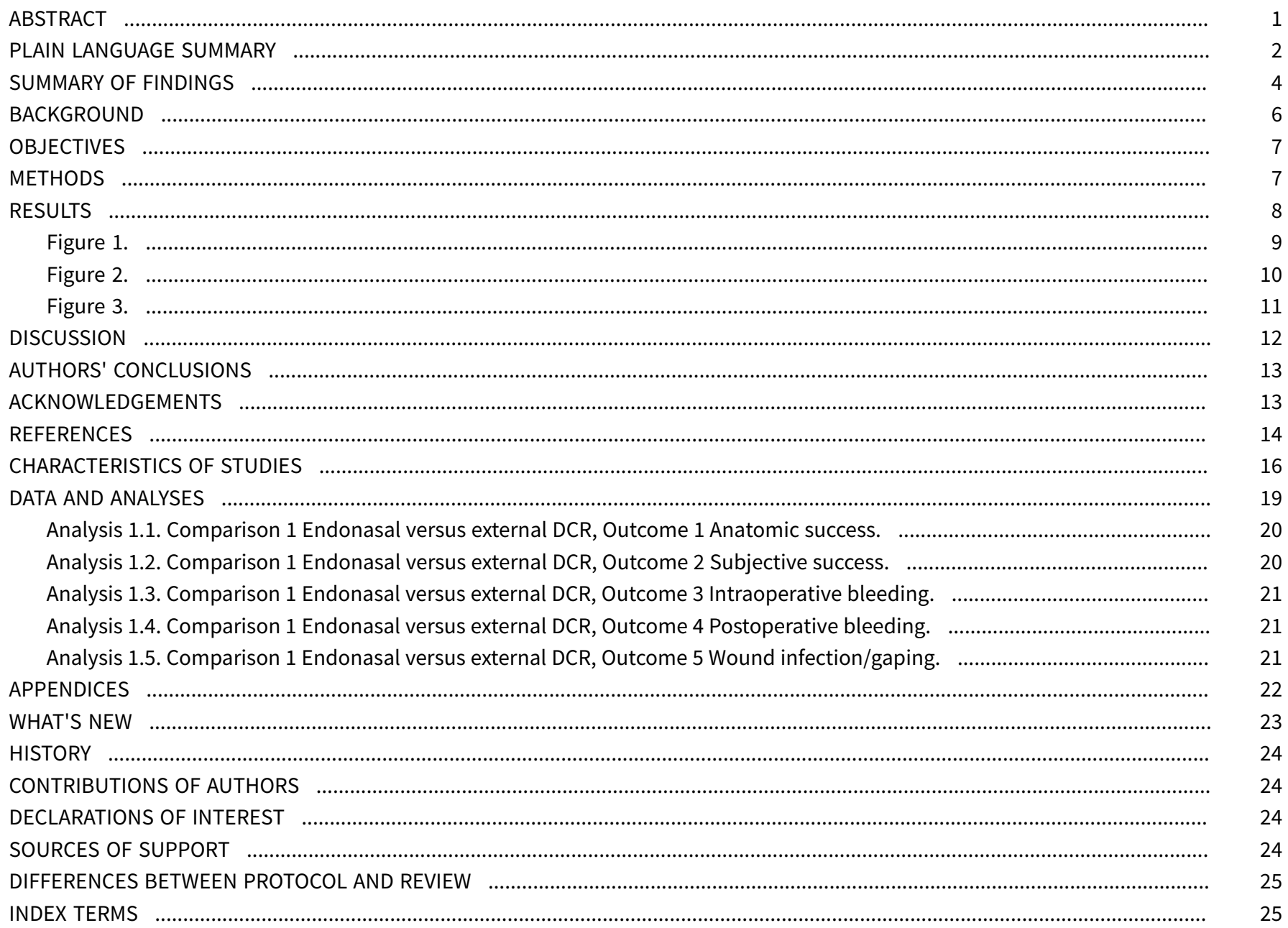


[Intervention Review]

\section{Endonasal versus external dacryocystorhinostomy for nasolacrimal duct obstruction}

Lona Jawaheer ${ }^{1}$, Caroline J MacEwen ${ }^{2}$, Deepa Anijeet ${ }^{1}$

1Ophthalmology Department, Gartnavel General Hospital, Glasgow, UK. 2Department of Ophthalmology, Ninewells University Hospital, Dundee, UK

Contact: Lona Jawaheer, Ophthalmology Department, Gartnavel General Hospital, 1053 Great Western Road, Glasgow, G12 0YN, UK. lona_j@hotmail.com, lonajawaheer@doctors.org.uk.

Editorial group: Cochrane Eyes and Vision Group.

Publication status and date: New search for studies and content updated (no change to conclusions), published in Issue 2, 2017.

Citation: Jawaheer L, MacEwen CJ, Anijeet D. Endonasal versus external dacryocystorhinostomy for nasolacrimal duct obstruction. Cochrane Database of Systematic Reviews 2017, Issue 2. Art. No.: CD007097. DOI: 10.1002/14651858.CD007097.pub3.

Copyright (c) 2017 The Cochrane Collaboration. Published by John Wiley \& Sons, Ltd.

\section{A B S T R A C T}

\section{Background}

A dacryocystorhinostomy (DCR) procedure aims to restore drainage of tears by bypassing a blockage in the nasolacrimal duct, through the creation of a bony ostium that allows communication between the lacrimal sac and the nasal cavity. It can be performed using endonasal or external approaches. The comparative success rates of these two approaches have not yet been established and this review aims to evaluate the relevant up-to-date research.

\section{Objectives}

The primary aim of this review is to compare the success rates of endonasal DCR with that of external DCR. The secondary aim is to compare the complication rates between the two procedures.

\section{Search methods}

We searched CENTRAL (which contains the Cochrane Eyes and Vision Group Trials Register) (2016, Issue 8), Ovid MEDLINE, Ovid MEDLINE InProcess and Other Non-Indexed Citations, Ovid MEDLINE Daily, Ovid OLDMEDLINE (January 1946 to 22 August 2016), Embase (January 1980 to 22 August 2016), Latin American and Caribbean Health Sciences Literature Database (LILACS) (January 1982 to 22 August 2016), Web of Science Conference Proceedings Citation Index- Science (CPCI-S) (January 1990 to 22 August 2016), the ISRCTN registry (www.isrctn.com/ editAdvancedSearch), ClinicalTrials.gov (www.clinicaltrials.gov) and the World Health Organization (WHO) International Clinical Trials Registry Platform (ICTRP) (www.who.int/ictrp/search/en). We did not use any date or language restrictions in the electronic searches for trials. We last searched the electronic databases on 22 August 2016. We requested or examined relevant conference proceedings for appropriate trials.

\section{Selection criteria}

We included all randomised controlled trials (RCTs) comparing endonasal and external DCRs.

\section{Data collection and analysis}

Two review authors independently assessed studies for eligibility and extracted data on reported outcomes. We attempted to contact investigators to clarify the methodological quality of the studies. We graded the certainty of the evidence using GRADE. 


\section{Main results}

We included two trials in this review. One trial from Finland compared laser-assisted endonasal DCR with external DCR, and one trial from India compared mechanical endonasal DCR (using punch forceps) with external DCR. The trials were poorly reported and it was difficult to judge the extent to which bias had been avoided.

Anatomic success was defined as the demonstration of a patent lacrimal passage on syringing, or endoscopic visualisation of fluorescein dye at the nasal opening of the anastomoses after a period of at least six months following surgery. Subjective success was defined as the resolution of symptoms of watering following surgery after a period of at least six months. Both included trials used anatomic patency demonstrated by irrigation as a measure of anatomic success. Different effects were seen in these two trials $\left(I^{2}=76 \%\right)$. People receiving laser-assisted endonasal DCR were less likely to have a successful operation compared with external DCR (63\% versus $91 \%$; risk ratio (RR) $0.69,95 \%$ confidence intervals (CI) 0.52 to 0.92 ; 64 participants). There was little or no difference in success comparing mechanical endonasal DCR and external DCR (90\% in both groups; RR 1.00, Cl 0.81 to 1.23; 40 participants). We judged this evidence on success to be very low-certainty, downgrading for risk of bias, imprecision and inconsistency. The trial from Finland also assessed subjective improvement in symptoms following surgery. Resolution of symptoms of watering in outdoor conditions was reported by $84 \%$ of the participants in the external DCR group and 59\% of those in the laser-assisted endonasal DCR group (RR 0.70, Cl 0.51 to 0.97; 64 participants, low-certainty evidence).

There were no cases of intraoperative bleeding in any participant in the trial that compared laser-assisted endonasal DCR to external DCR. This was in contrast to the trial comparing mechanical endonasal DCR to external DCR in which $45 \%$ of participants in both groups experienced intraoperative bleeding (RR $1.00,95 \% \mathrm{Cl} 0.50$ to $1.98 ; 40$ participants). We judged this evidence on intraoperative bleeding to be very low-certainty, downgrading for risk of bias, imprecision and inconsistency.

There were only two cases of postoperative bleeding, both in the external DCR group (RR 0.33, 95\% Cl 0.04 to 3.10; participants = 104; studies $=2)$. There were only two cases of wound infection/gaping, again both in the external DCR group $(\mathrm{RR} 0.20, \mathrm{Cl} 0.01$ to 3.92 ; participants $=$ 40 ; studies $=1$ ). We judged this evidence on complications to be very low-certainty, downgrading one level for risk of bias and two levels for imprecision due to the very low number of cases.

\section{Authors' conclusions}

There is uncertainty as to the relative effects of endonasal and external DCR. Differences in effect seen in the two trials included in this review may be due to variations in the endonasal technique, but may also be due to other differences between the trials. Future larger RCTs are required to further assess the success and complication rates of endonasal and external DCR. Different techniques of endonasal DCR should also be assessed, as the choice of endonasal technique can influence the outcome. Strict outcome criteria should be adopted to assess functional and anatomical outcomes with a minimal follow-up of six months.

\section{PLAIN LANGUAGE SUMMARY}

\section{Different surgical techniques for treating blockage of the tear duct}

\section{What is the aim of this review?}

The aim of this Cochrane Review was to compare two different surgical techniques for treating blockage of the tear (nasolacrimal) duct. Cochrane researchers collected and analysed all relevant studies to answer this question and found two studies.

\section{Key messages}

It is unclear whether or not endonasal dacryocystorhinostomy (DCR) is a better way of treating tear duct obstruction than external DCR (very low-certainty evidence), nor is it clear whether endonasal DCR reduces the chance of complications such as bleeding or wound infection (very low-certainty evidence).

\section{What was studied in the review?}

The tear duct, or nasolacrimal passage, allows excess tears to drain away from the eye. If the tear duct gets blocked then the eye can water too much. Doctors can use a surgical procedure known as dacryocystorhinostomy (DCR) to treat the blocked tear duct. This operation creates a way for the tears to drain from the eye that bypasses the blockage. There are two ways of doing this operation: either by making a cut on the outside of the nose (external DCR); or by operating inside the nose, using an endoscope (a flexible tube with a light at the end) to see inside the nose (endonasal DCR) and creating an alternate drainage pathway using instruments (such as forceps or drill) or laser.

\section{What are the main results of the review?}

The review authors found two relevant studies. One study was from Finland and compared laser-assisted endonasal DCR with external DCR. One study was from India and compared mechanical endonasal DCR (using punch forceps) with external DCR.

The Cochrane researchers are uncertain whether endonasal DCR increases the chance of success compared with external DCR, or whether endonasal DCR reduces the chance of complications such as bleeding or wound infection. They judged the certainty of the evidence to be very low.

\section{How up-to-date is this review?}


The Cochrane researchers searched for studies that had been published up to 22 August 2016. 


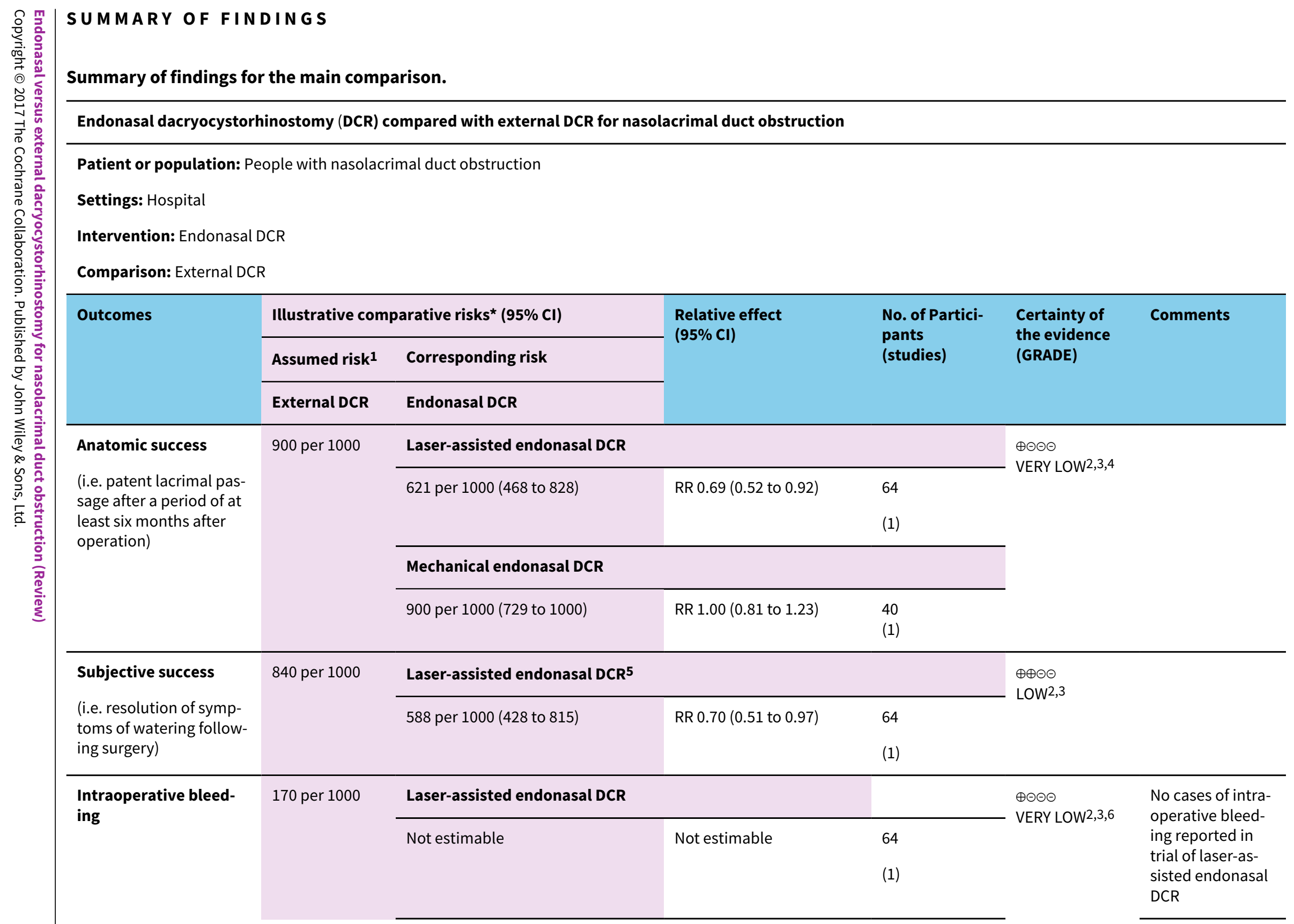




\begin{tabular}{|c|c|c|c|c|c|c|}
\hline \multirow[t]{2}{*}{$\delta \mathrm{m}$} & & \multicolumn{3}{|c|}{ Mechanical endonasal DCR } & & \\
\hline & & 170 per 1000 (85 to 337 ) & RR 1.00 (0.50 to 1.98$)$ & $\begin{array}{l}40 \\
(1)\end{array}$ & & \\
\hline Postoperative bleeding & 40 per 1000 & 13 per 1000 ( 2 to 124$)$ & $\operatorname{RR} 0.33$ (0.04 to 3.10$)$ & $\begin{array}{l}104 \\
(2)\end{array}$ & \multicolumn{2}{|l|}{$\begin{array}{l}\oplus \odot \odot \odot \\
\text { VERY LOW } 2,7\end{array}$} \\
\hline \multirow{4}{*}{$\begin{array}{l}\text { Wound infection/gap- } \\
\text { ing }\end{array}$} & \multirow[t]{4}{*}{40 per 1000} & \multicolumn{2}{|c|}{ Laser-assisted endonasal DCR } & & \multirow{4}{*}{$\begin{array}{l}\oplus \ominus \ominus \ominus \\
\text { VERY LOW } 2,7\end{array}$} & \multirow{2}{*}{$\begin{array}{l}\text { No cases of } \\
\text { wound infec- } \\
\text { tion/gaping re- } \\
\text { ported in trial of } \\
\text { laser-assisted en- } \\
\text { donasal DCR }\end{array}$} \\
\hline & & Not estimable & Not estimable & $\begin{array}{l}64 \\
(1)\end{array}$ & & \\
\hline & & \multicolumn{2}{|c|}{ Mechanical endonasal DCR } & & & \\
\hline & & 8 per 1000 ( 0 to 157$)$ & RR 0.20 (0.01 to 3.92) & $\begin{array}{l}40 \\
(1)\end{array}$ & & \\
\hline \multicolumn{7}{|c|}{ Cl: confidence interval; DCR: dacryocystorhinostomy; RR: risk ratio } \\
\hline \multicolumn{7}{|c|}{$\begin{array}{l}\text { GRADE Working Group grades of evidence } \\
\text { High-certainty: Further research is very unlikely to change our confidence in the estimate of effect. } \\
\text { Moderate-certainty: Further research is likely to have an important impact on our confidence in the estimate of effect and may change the estimate. } \\
\text { Low-certainty: Further research is very likely to have an important impact on our confidence in the estimate of effect and is likely to change the estimate. } \\
\text { Very low-certainty: We are very uncertain about the estimate. }\end{array}$} \\
\hline
\end{tabular}

1The assumed control risk was estimated from the control group in the included studies.

2We downgraded one level for study limitations because the methods used for random sequence generation, allocation concealment and masking were not clearly described. 3 We downgraded one level for imprecision because the number of participants enrolled in these trials was low and the estimate of effect was imprecise.

${ }^{4}$ We downgraded one level for inconsistency as there was clinical and statistical heterogeneity in the two trials (test for interaction $\mathrm{P}=0.04$ ).

5 Subjective success was not reported in the trial of mechanical endonasal DCR (Moras 2011).

6 We downgraded one level for inconsistency as there was clinical heterogeneity in the two trials. There were no cases of intraoperative haemorrhage in the trial of laser-assisted endonasal DCR.

7 We downgraded two levels for imprecision as there were only two events recorded, both in the external DCR group. 


\section{B A C K G R O U N D}

\section{Description of the condition}

Tears from the conjunctival sac pass through the lacrimal puncta in the upper and lower lids to the upper and lower lacrimal canaliculi, then to the common canaliculi to empty into the lacrimal sac, located in the lacrimal fossa. From the lacrimal sac, tears pass to the nasolacrimal duct along the lateral wall of the nose to open at the inferior meatus. Obstruction anywhere along this course can result in excessive watering from the eyes as well as recurrent infections. In a retrospective study of 150 patients who underwent external DCR for nasolacrimal duct obstruction (Tarbet 1995), it was found that the most common presenting symptoms included excessive watering (86\%), and either acute or chronic infections (about 30\%). The prevalence of nasolacrimal duct obstruction was also found to increase with age and to have a female preponderance.

\section{Description of the intervention}

Nasolacrimal duct obstruction is treated by dacryocystorhinostomy (DCR). This is a surgical technique that involves the creation of an alternative route for drainage of tears, between the lacrimal sac and nasal cavity, bypassing the nasolacrimal duct. This can be done either by an external approach (external DCR) or through the nasal cavity using an endoscope or a microscope (endonasal DCR). Functional nasolacrimal duct obstruction is due to poor functioning of the lacrimal pump mechanism. Treatment with DCR in this situation can give variable results.

\section{External DCR}

The ophthalmologist generally performs this procedure. The technique was originally described in 1904 (Toti 1904), and was later modified by the addition of suturing of the mucosal flaps (Dupuy-Dutemps 1921), thus forming an epithelium-lined fistula. Several case series have estimated the success rate of external DCR to be between $70 \%$ and 95\% (Ben Simon 2005; Cokkeser 2000; Dolman 2003; Tarbet 1995; Tsirbas 2004; Yigit 2007).

\section{Endonasal DCR}

The endonasal approach was introduced in 1893 by Caldwell (Caldwell 1893), and modified by West (West 1910), and later, Halle (Halle 1914). The approach failed to gain popularity due to poor access to the nasal cavity. With the advent of the nasal endoscope (Stammberger 1986), and functional endoscopic sinus surgery in the early 1990s (Kennedy 1985), there was renewed interest in endonasal DCR. McDonogh 1989 introduced endonasal DCR in its present form. The reported success rate for endonasal DCR ranges from 63\% to 96\% (Ben Simon 2005; Hartikainen 1998; Sham 2000; Yuce 2013). Endonasal DCR can also be performed by using a microscope or by direct visualisation using a surgical loupe that magnifies the surgical field. Various techniques, such as bone drills and lasers to vaporise bone have been used to create the functioning passage from the lacrimal sac into the nasal cavity in the endonasal procedure. Argon blue green; potassium titanyl phosphate; carbon dioxide; holmium: yttrium-aluminium-garnet (YAG); neodymium:YAG; and combined carbon dioxide neodymium ( $\mathrm{CO}^{2}$-Nd): YAG are some examples of the lasers used (Boush 1994; Kong 1994; Metson 1994; Muellner 2000; Pearlman 1997; Reifler 1993; Seppa 1994; Woog 1993). The outcome of endonasal DCR can vary depending on the method employed to create the ostium (Huang 2014;Maini 2007).

\section{Endonasal versus external DCR}

The advantages of endonasal DCR over external DCR are: limited invasiveness, less intraoperative bleeding, shorter operative time and preservation of pump function of the orbicularis oculi muscle. Absence of an external scar, minimal morbidity and low complication rate have made endonasal DCR popular (a newer technique of external DCR has recently been described, whereby a periciliary incision is made, avoiding the external cutaneous scar of conventional external DCR (Ng 2015)). The disadvantages of endonasal DCR include: a relatively smaller opening between the lacrimal sac and nasal cavity, higher recurrence rate, high equipment cost, and the fact that it is a more difficult procedure to learn. The relatively smaller opening, steeper learning curve and technique used to create the opening may affect the success rates.

\section{Intraoperative factors}

A few intraoperative factors are thought to influence the outcome of the surgery. For example, augmentation with antimitotic agents (5-Fluorouracil (5-FU) or mitomycin C (MMC)) has been reported in a few cohort studies. Henson 2007 reported a success rate of $87.5 \%$ in their non-comparative study investigating the use of endocanalicular DCR employing diode laser and MMC. Watts 2001 found external DCR gave better surgical outcomes (95\%) compared with 5-FU augmented Holmium-YAG laser-assisted endonasal DCR (64\%). Roozitalab 2004 found no benefit to using intraoperative MMC in external DCR in their comparative study; success in the group randomised to MMC was $90.5 \%$ compared to $92.4 \%$ in the group randomised to no MMC. A controlled study by Qin 2010a yielded a significantly higher rate of success with the use of MMC in endoscopic endonasal DCR using nasolacrimal duct stent placement $(95.2 \%$ in treatment group versus $85.8 \%$ in control group).

The use of silicone intubation of the lacrimal passages is another option available to ophthalmologists performing DCR. However, there appears to be no evidence in support of this practice. Studies that compared the effectiveness of DCR with and without silicone intubation did not find any advantage to intubation (Saiju 2009; Smirnov 2006; Unlu 2009). The added cost and follow-up for the patient can be avoided by omitting this step. Chen 2009 described a new technique of recanalisation of nasolacrimal duct obstruction using a lacrimal canaliser. The authors claim this technique to be simple, non-invasive and with comparable success rates and adverse events to external DCR.

Other adjunctive measures to improve the success of DCR include concomitant endonasal procedures such as middle turbinectomy/ endonasal mechanical enlargement of the neo-ostium, as well as the suturing of mucosal flaps.

\section{How the intervention might work}

DCR creates an alternate passage between the lacrimal sac and nasal cavity, thus bypassing the obstruction along the nasolacrimal duct. This helps the tears to drain away from the eye.

\section{Why it is important to do this review}

There is no clear consensus on the choice of surgery type for treatment of nasolacrimal duct obstruction. 


\section{O B JECTIVES}

The primary aim of this review is to compare the success rates of endonasal DCR with that of external DCR. The secondary aim is to compare the complication rates between the two procedures.

\section{METHODS}

\section{Criteria for considering studies for this review}

\section{Types of studies}

We included all randomised controlled trials (RCTs) which compared the success rates of endonasal DCR with that of external DCR.

\section{Types of participants}

We included participants of all age groups, diagnosed with primary post-canalicular obstruction of the lacrimal passages. We excluded studies that included participants who had previous surgical procedures to the lacrimal apparatus.

\section{Types of interventions}

We compared endonasal dacryocystorhinostomy (DCR) using a drill, curette or laser to create a communication between the lacrimal sac and nasal cavity, with external DCR using the standard technique. We included studies with a follow-up period of six months to two years.

\section{Types of outcome measures}

\section{Primary outcomes}

1. Anatomic success (defined as patent lacrimal passage on syringing, or endoscopic visualisation of fluorescein dye at the nasal opening of the anastomoses, after a period of at least six months following surgery).

2. Subjective success (resolution of symptoms of watering following surgery, after a period of at least six months).

We considered recurrence of dacryocystitis as failure.

\section{Secondary outcomes}

We collected and collated data on the following adverse events for the two types of interventions.

1. Intraoperative bleeding requiring intervention.

2. Postoperatve bleeding requiring intervention (within seven days of surgery).

3. Wound infection/gaping.

\section{Search methods for identification of studies}

\section{Electronic searches}

We searched CENTRAL (which contains the Cochrane Eyes and Vision Group Trials Register) (2016, Issue 8), Ovid MEDLINE, Ovid MEDLINE In-Process and Other Non-Indexed Citations, Ovid MEDLINE Daily, Ovid OLDMEDLINE (January 1946 to 22 August 2016), Embase (January 1980 to 22 August 2016), Latin American and Caribbean Health Sciences Literature Database (LILACS) (January 1982 to 22 August 2016), Web of Science Conference Proceedings Citation Index- Science (CPCI-S) (January 1990 to 22 August 2016), the ISRCTN registry (www.isrctn.com/
editAdvancedSearch), ClinicalTrials.gov (www.clinicaltrials.gov) and the World Health Organization (WHO) International Clinical Trials Registry Platform (ICTRP) (www.who.int/ictrp/search/en). We did not use any date or language restrictions in the electronic searches for trials. We last searched the electronic databases on 22 August 2016.

See: Appendices for details of search strategies for CENTRAL (Appendix 1), MEDLINE (Appendix 2), Embase (Appendix 3), LILACS (Appendix 4), CPCI-S (Appendix 5), ISRCTN (Appendix 6), ClinicalTrials.gov (Appendix 7) and the ICTRP (Appendix 8).

\section{Searching other resources}

We searched the proceedings of the Association for Research in Otolaryngology (ARO), available from 1992 to 2008; there were no relevant abstracts. Abstracts from other conferences, including the British Oculoplastic Surgery Society (BOPSS), the European Society of Ophthalmic Plastic and Reconstructive Surgery (ESOPRS) and the American Society of Ophthalmic Plastic and Reconstructive Surgery (ASOPRS) were not available for searching.

\section{Data collection and analysis}

We followed the review protocol, published in 2008 (Anijeet 2008), to select trials for this update.

\section{Selection of studies}

For the 2017 update, two review authors (LJ and DA) independently screened the titles and abstracts retrieved by the searches to establish whether they met the criteria as defined in the section, 'Criteria for considering studies for this review'. The two review authors resolved any disagreement by discussion and obtained the full-text copies of definitely or potentially relevant studies.

\section{Data extraction and management}

For this update, two review authors (LJ and DA) independently assessed studies for eligibility and extracted data into Review Manager 5 on reported outcomes (RevMan 2014). Disagreements were resolved by discussion among review authors. We attempted to contact trial authors of the included studies if any clarification of study details were required.

We extracted the following data from the included studies.

1. Trial characteristics: design, randomisation, allocation concealment, masking (blinding).

2. Interventions: standard procedures for endonasal DCR and external DCR.

3. Outcomes: success rates as described in the primary outcomes, intraoperative and postoperative complications (intraoperative and postoperative bleeding; wound infection or wound dehiscence).

\section{Assessment of risk of bias in included studies}

Two review authors (LJ and DA) independently assessed study quality according to the guidelines in Chapter 8 of the Cochrane Handbook for Systematic Reviews of Interventions (Higgins 2011). The quality parameters we assessed were allocation concealment, method of allocation, completeness of follow-up, masking of participants and outcome assessors, and documentation of complications. The review authors were not masked to the study 
authors or results of the study. We graded these parameters as 'low' risk of bias, 'high' risk of bias or 'unclear'. The review authors made attempts to contact study authors to clarify data.

\section{Measures of treatment effect}

We summarised data from studies collecting similar outcome measures and with similar follow-up times (minimum of six months). We summarised the outcome data using risk ratios (RRs).

\section{Unit of analysis issues}

We attempted to contact the authors of the included studies to clarify possible unit of analysis issues (method of randomisation/ allocation sequence concealment/limiting performance or detection bias), but were unsuccessful.

\section{Dealing with missing data}

We attempted to contact the trial authors to try and retrieve relevant data. If we were unable to retrieve the data, we included the study, but designated it as a study with missing data when discussing the results.

\section{Assessment of heterogeneity}

We formally assessed heterogeneity using $\mathrm{Chi}^{2}$ test. We also calculated the $\mathrm{I}^{2}$ statistic, which describes the percentage of the variability in effect estimates that is due to heterogeneity rather than chance, and interpreted it as follows: $0 \%$ to $40 \%$ - might not be important; $30 \%$ to $60 \%$ - may represent moderate heterogeneity; $50 \%$ to $90 \%$ - may represent substantial heterogeneity; $75 \%$ to $100 \%$ - considerable heterogeneity.

\section{Assessment of reporting biases}

As only two trials were included, we did not construct a funnel plot.

\section{Data synthesis}

We pooled data from the individual studies using a fixed-effect model. We used the fixed-effect model (Mantel-Haenszel) to determine RRs of dichotomous data from the included study. We chose the Mantel-Haenszel model because of the low event rates and small trial sizes.

\section{Subgroup analysis and investigation of heterogeneity}

We conducted one subgroup analysis which was specified in our protocol (Anijeet 2008). We compared external DCR and endonasal DCR using either the laser or mechanical technique.The $\mathrm{I}^{2}$ statistic for subgroup differences was $76 \%$ (considerable heterogeneity).

\section{Sensitivity analysis}

In our protocol we planned to conduct a sensitivity analysis to assess the consequence of including missing data, or data with ambiguous results, or data analysed using different statistical methods. However, we did not conduct any sensitivity analyses because of the low number of included trials.

\section{'Summary of findings' tables}

We prepared a 'Summary of findings' table, presenting relative and absolute risks. The following outcomes were included in the table: anatomic success, subjective success, intraoperative bleeding, postoperative bleeding, and wound infection/gaping. Using GRADEpro software (GRADEpro GDT 2014), two review authors independently graded the overall certainty of the evidence for each outcome by applying the GRADE classification (Atkins 2004). GRADE includes consideration of study limitations, imprecision, inconsistency, indirectness and publication bias. We used the following four grades.

High-certainty: Further research is very unlikely to change our confidence in the estimate of effect.

Moderate-certainty: Further research is likely to have an important impact on our confidence in the estimate of effect and may change the estimate.

Low-certainty: Further research is very likely to have an important impact on our confidence in the estimate of effect and is likely to change the estimate.

Very low-certainty: We are very uncertain about the estimate.

\section{RES U L T S}

\section{Description of studies}

\section{Results of the search}

The electronic searches from December 2010 identified 881 references. The Cochrane Information Specialist scanned the search results and removed any references which were not relevant to the scope of the review. Two review authors independently reviewed the remaining references and obtained the full-text copies of four studies. We included one randomised controlled trial (RCT) that met the inclusion criteria of the review and excluded three studies.

In an updated search, run in August 2016, we identified 898 new records (Figure 1). The Cochrane Information Specialist removed 186 duplicate records, screened the remaining 712 records and removed 582 references that were not relevant to the review. We screened the remaining 130 references and discarded 123 reports, as they were not relevant. We obtained seven full-text reports for further assessment. We included one new study, Moras 2011, and excluded the following four studies: Balikoglu-Yilmaz 2015; Derya 2013; Tang 2015; Taskin 2011 as they did not meet the inclusion criteria, see 'Characteristics of excluded studies' table for details.

In the previous version of the review (Anijeet 2011), a Chinese study by Qin 2010 was awaiting assessment. Having reviewed the abstract, it was agreed that this study was found to pertain to the effects of using mitomycin C in endonasal DCR, and was therefore removed from the shortlisted articles. In this update, we identified two studies (Cui 2013; Zhou 2015) for which we required further clarification regarding the methods. We have therefore placed these studies in the Characteristics of studies awaiting classification section. For Cui 2013, we are unsure of the methods of randomisation and for Zhou 2015, we would like details of how the participants were randomised as this information is missing from the full-text report. We attempted to contact the authors, but to date have not received responses for these two trials. 
Figure 1. Study flow diagram.

1 study included in
previous version of the
review (searches as of
December 2010). 1
study awaiting
assessment*

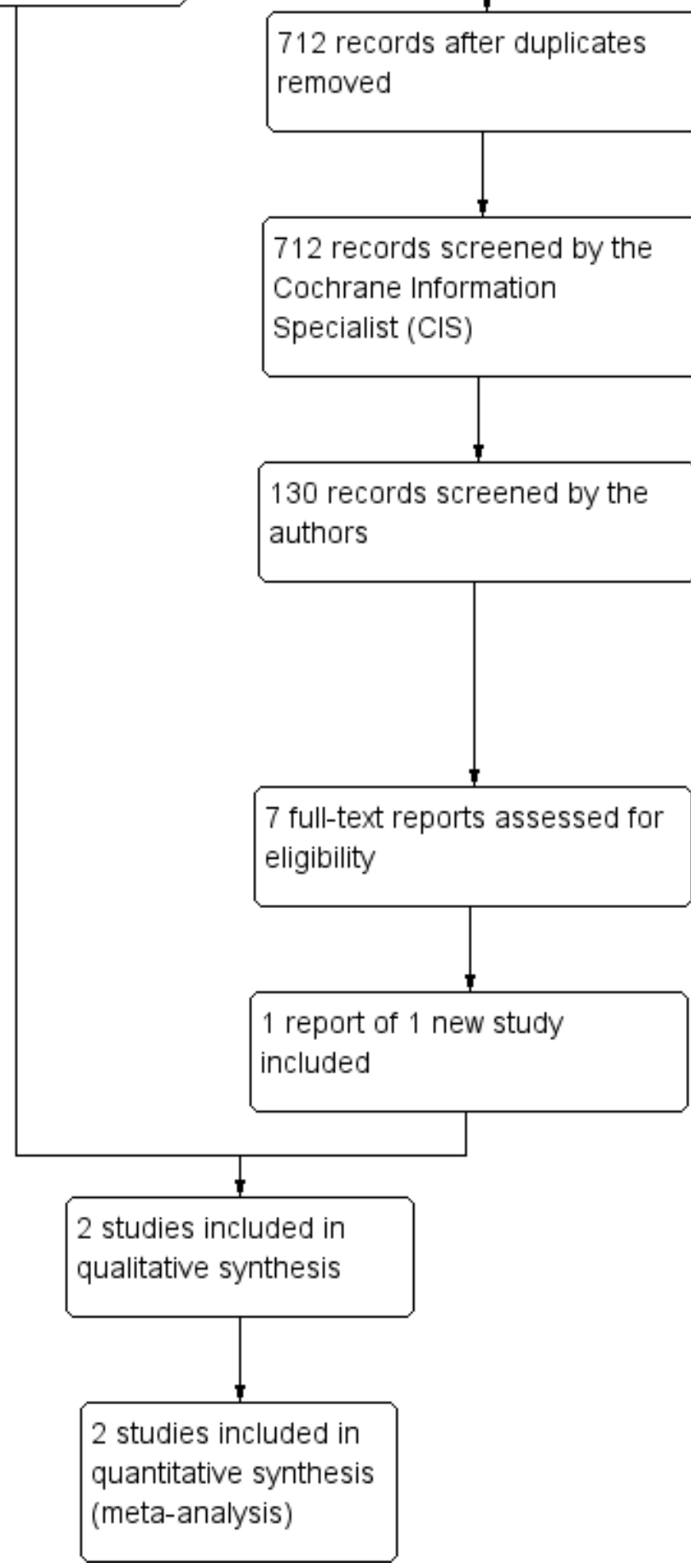

898 records identified through electronic database searching (December 2010 to August 2016)

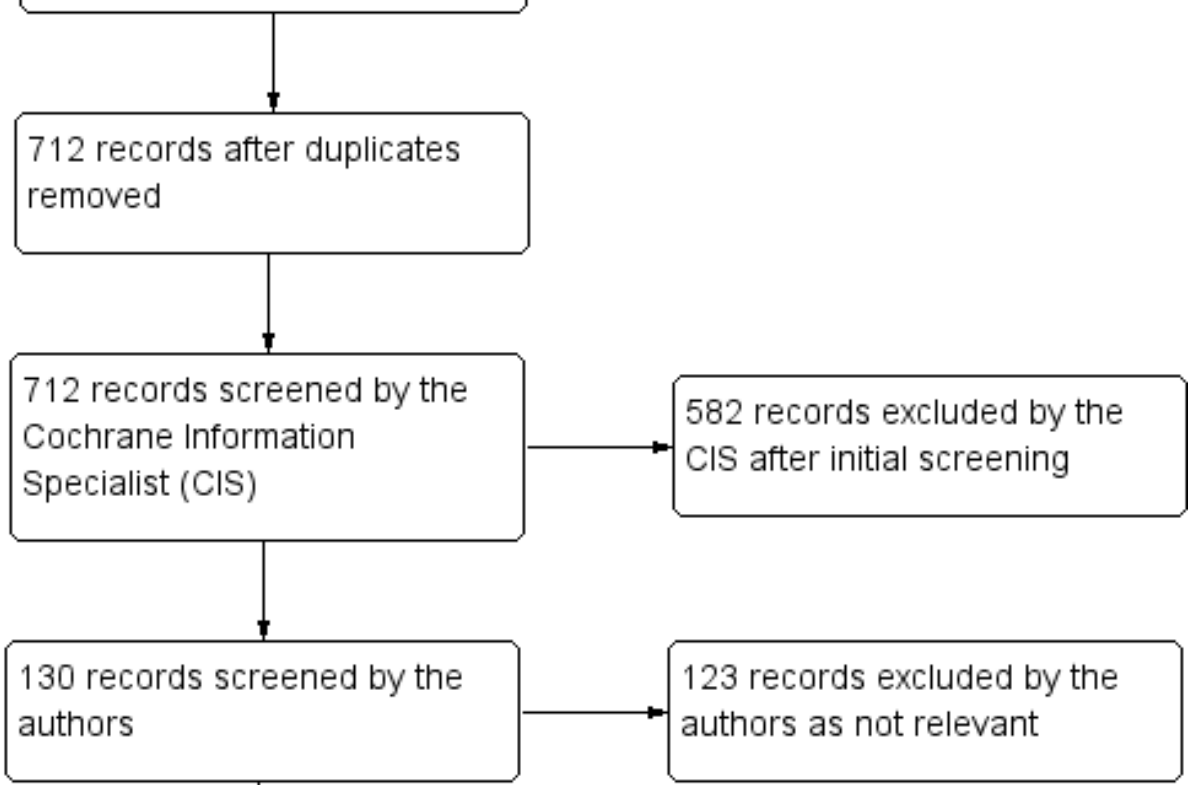
6 full-text reports excluded, with reasons. 1 study previously awaiting assessment has now been excluded* 


\section{Included studies}

See: 'Characteristics of included studies' tables.

We included two studies that met our inclusion criteria (Hartikainen 1998; Moras 2011).

\section{Design}

Both studies were RCTs.

\section{Sample sizes}

Hartikainen 1998 randomised participants to laser-assisted endonasal dacryocystorhinostomy (DCR) (32 procedures) or external DCR (32 procedures). Moras 2011 randomised 40 participants to be treated either by mechanical endonasal DCR) (20 procedures) or EXT DCR (20 procedures).

\section{Setting}

Hartikainen 1998 was conducted in a single unit in Finland. Moras 2011 was conducted in India.

\section{Participants}

In Hartikainen 1998, the mean age of the study group was 65 years (range 23 to 89). The male to female ratio was 1:5.

Moras 2011 identified 40 participants with primary acquired nasolacrimal duct obstruction or chronic dacryocystitis who presented to the ophthalmology and Ear, Nose and Throat (ENT) outpatient departments of Fr. Muller Medical College, Mangalore, India. Eighty per cent of the participants were female, and the age of the participants ranged from 16 to 68 years, with the majority $(62.5 \%)$ being in the 30 to 50 age group.

\section{Interventions}

Hartikainen 1998

Endonasal laser-assisted DCR was compared to external DCR. The external DCR was performed by an ophthalmologist and the endonasal DCR was performed by an otolaryngologist and ophthalmologist. The endonasal DCR used a continuous wave CO2$\mathrm{Nd}$ : YAG combined laser to fashion the bony ostium and nasal mucosal opening.

Moras 2011

Endonasal mechanical DCR was compared to external DCR. The endonasal DCR was performed using punch forceps to create the ostium in the lacrimal bone.

\section{Outcomes}

The outcomes in Hartikainen 1998 were patent lacrimal passage on irrigation at one year (anatomic success), and patient-reported symptomatic improvement.

The outcome in Moras 2011 was patent lacrimal drainage system on sac syringing at the end of six months.

\section{Excluded studies}

We excluded eight studies in total, and details (including reason for exclusion) can be found in the 'Characteristics of excluded studies' tables.

\section{Risk of bias in included studies}

See Figure 2; Figure 3.

\section{Figure 2. Risk of bias graph: review authors' judgements about each risk of bias item presented as percentages} across all included studies.

Random sequence generation (selection bias)

Allocation concealment (selection bias)

Blinding (performance bias and detection bias)

Incomplete outcome data (attrition bias)

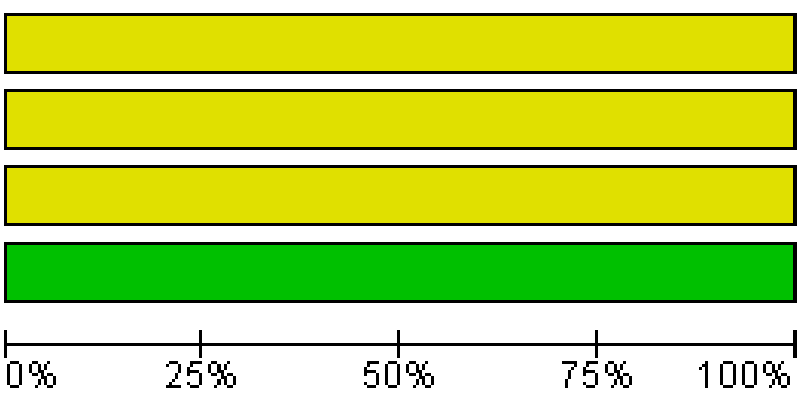


Figure 3. Risk of bias summary: review authors' judgements about each risk of bias item for each included study.

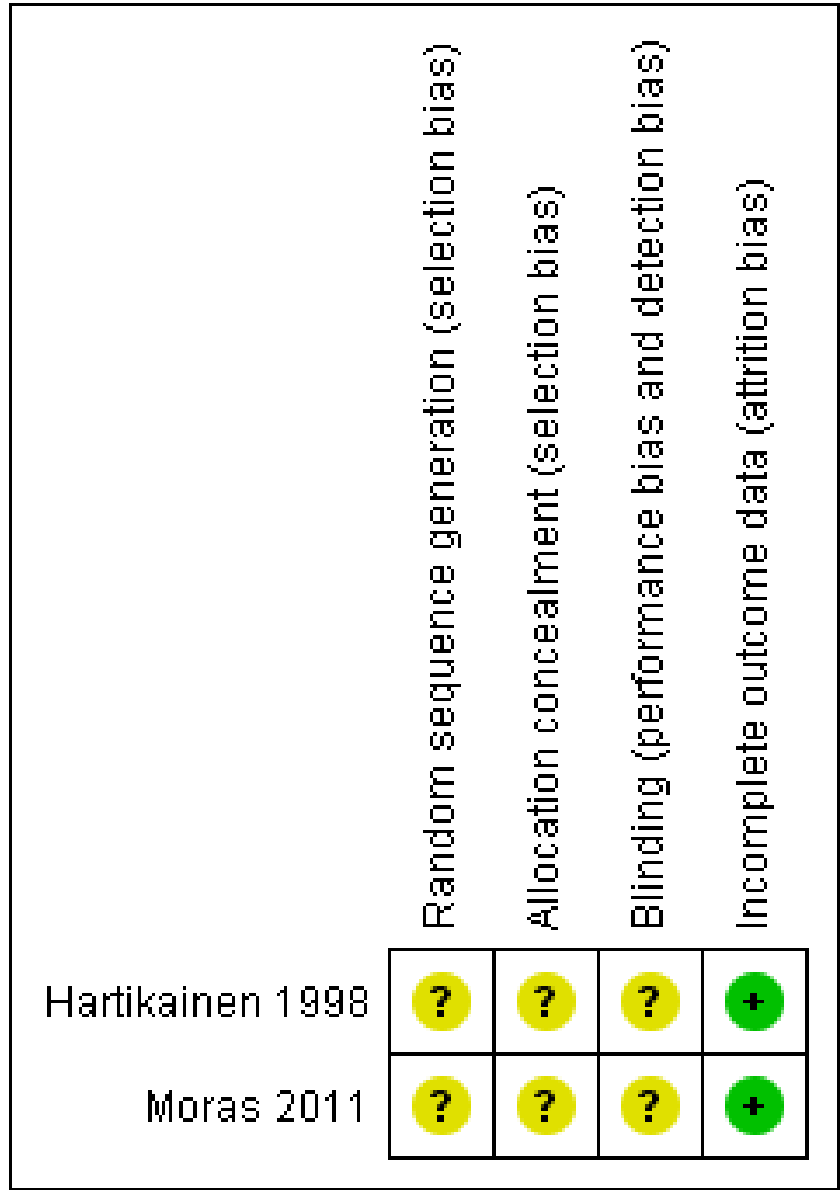

Overall, the risk of bias for the two included studies was unclear. We could not contact the corresponding authors for the studies, and therefore we could not resolve unit of analysis issues, and errors may have been introduced.

\section{Allocation}

We assessed allocation concealment and the method of randomisation as unclear; no further information was available.

\section{Blinding}

Masking (blinding) with respect to the type of operation was not possible with the surgeons and there was no description of masking of either the participants or outcome assessors in either trial. As no further information was available, we assessed the risk of bias as unclear.

\section{Incomplete outcome data}

Outcome data for all three parameters - success, intraoperative and postoperative bleeding appeared to be complete in the trials.

\section{Effects of interventions}

See: Summary of findings for the main comparison
Endonasal dacryocystorhinostomy (DCR) versus external DCR Primary outcomes

\section{Anatomic success}

In the two included trials, 104 procedures were performed; 52 each of endonasal dacryocystorhinostomy (DCR) and external DCR.

In Hartikainen 1998, the anatomic success rates in the external DCR group were $100 \%(32 / 32)$ at six months and $91 \%(29 / 32)$ at 12 months postoperatively. In the laser-assisted endonasal DCR group, they were $78 \%(25 / 32)$ at six months and $63 \%(20 / 32)$ at 12 months postoperatively. The risk ratio (RR) for the 12 -month anatomic success rates for external DCR versus laser-assisted endonasal DCR was 0.69 , 95\% confidence interval $(\mathrm{Cl}) 0.52$ to 0.92 , 64 participants, 1 study.

In Moras 2011, the success rate six months after the operation was $90 \%$ (18 out of 20 procedures) for both types of DCR: RR 1.00, 95\% $\mathrm{Cl} 0.81$ to 1.23 , 40 participants, 1 study (data for 12 -month followup were not available, as in Hartikainen 1998).

We judged this evidence on success to be very low-certainty, downgrading for risk of bias, imprecision and inconsistency (Summary of findings for the main comparison; Analysis 1.1). 
The six-month success rate for endonasal laser-assisted DCR in Hartikainen 1998 (32 participants) was lower than for endonasal mechanical DCR in Moras 2011 (20 participants) - 78\% versus 90\%.

\section{Subjective success}

Hartikainen 1998 reported the rate of subjective success (resolution of watering in outdoor conditions) at the final postoperative visit. This was $84 \%(27 / 32)$ in the external DCR group and 59\% (19/32) in the laser-assisted endonasal DCR group: RR $0.70,95 \% \mathrm{Cl} 0.51$ to 0.97, 64 participants, 1 study. We judged this evidence to be lowcertainty, downgrading for risk of bias and imprecision (Summary of findings for the main comparison; Analysis 1.2).

The difference in effect between the two trials is discussed further in the 'Discussion' section below.

\section{Secondary outcomes}

\section{Intraoperative bleeding}

There were no cases of significant intraoperative bleeding in either the laser-assisted endonasal (32 participants) or the external DCR group (32 participants) in Hartikainen 1998 (RR not estimable), but in Moras 2011, equal numbers of participants in the mechanical endonasal and external DCR group $(9 / 20 ; 45 \%)$ experienced intraoperative bleeding (RR $1.00,95 \% \mathrm{Cl} 0.50$ to 1.98 , 40 participants, 1 study). We judged this evidence to be very lowcertainty, downgrading for risk of bias, imprecision and uncertainty (Summary of findings for the main comparison; Analysis 1.3).

\section{Postoperative bleeding}

Overall, none of the 52 participants in the endonasal group experienced postoperative bleeding, whereas in the external DCR group, 1 participant in each study experienced bleeding. Of these 2 participants, one required hospitalisation and endonasal tamponade. The risk ratios for postoperative bleeding in endonasal versus external DCR was 0.33 ( $95 \% \mathrm{Cl} 0.01$ to $7.89,64$ participants) for Hartikainen 1998, and 0.33 ( $95 \% \mathrm{Cl} 0.01$ to $7.72,40$ participants) in Moras 2011.

We judged this evidence to be very low-certainty, downgrading for risk of bias and imprecision (Summary of findings for the main comparison; Analysis 1.4).

\section{Wound infection/gaping}

In the external DCR group, 2/52 participants experienced wound infection/gaping (1 participant in each study). None of the 52 participants in the endonasal DCR group experienced these wound complications The risk ratios for wound infection/ gaping in endonasal versus external DCR was not estimable for Hartikainen 1998 , and 0.20 (95\% Cl 0.01 to 3.92, 40 participants) in Moras 2011.We judged this evidence to be very low-certainty, downgrading for risk of bias and imprecision (Summary of findings for the main comparison; Analysis 1.5).

\section{DISCUSSION}

We included two randomised controlled trials (RCTs) comparing the successes and complications of endonasal versus external dacryocystorhinostomy (DCR) for nasolacrimal duct obstruction in this updated review.
A few different ways exist of assessing postoperative success for nasolacrimal duct obstruction (Fayers 2009; Moore 2002). Objective methods include the demonstration of patency of lacrimal system by syringing, and demonstration of functional success by endoscopic visualisation of fluorescein dye at the nasal opening of the anastomoses. Alternatively, subjective success can be assessed by asking patients about the improvement in epiphora following the operation. Few studies exist regarding the long-term success of DCR.

The impact on quality of life of the patients undergoing the procedures was not assessed in either included trial. Other studies have compared quality of life outcomes between external DCR and endonasal DCR. Mathew 2004 did a retrospective telephone interview with 20 patients who had undergone endonasal mechanical DCR and 42 who had undergone external DCR - they found that patient satisfaction rates ( $70 \%$ and $86 \%$ respectively) were comparable between the 2 procedures as there was no significant difference.

The avoidance of a facial scar is an important advantage of endonasal DCR. Two studies (Bakri 1999; Hii 2012) were found which assessed postoperative quality of life following endonasal or external DCR using the Glasgow Benefit Inventory. This validated questionnaire is used widely for otorhinolaryngological procedures. Although it does not directly assess patients' satisfaction with cosmesis following the procedures, it does assess the patients' perception of psychological, social and physical wellbeing by including outcomes such as feelings of self-confidence, feelings of embarrassment in a group of people, confidence regarding job opportunities and participation in social activities.

Bakri 1999 reported mean scores of +16.8 for patients in the endonasal laser DCR and +23.2 for patients in the external DCR group - this difference was not significant. Hii 2012 also found comparable outcomes between endonasal mechanical and external DCR groups (mean score of +24.1 and +16.1 respectively; no significant difference). This would suggest that the presence of the scar following external DCR does not appear to have a huge impact on patients' levels of post-operative satisfaction.

\section{Summary of main results}

Our review shows different anatomic success rates in the two included trials $(12=76 \%)$. For the study comparing endonasal laserassisted DCR with external DCR (Hartikainen 1998), the anatomic success rates 12 months postoperatively were $91 \%$ and $63 \%$, respectively (risk ratio (RR) $0.69,95 \%$ confidence interval $(\mathrm{Cl}) 0.52$ to $0.92,64$ participants), and for the study comparing endonasal mechanical DCR with external DCR (Moras 2011), the anatomic success rates six months postoperatively were $90 \%$ for both studies (RR 1.00, Cl 0.81 to 1.23 , 40 participants).

Hartikainen 1998 also assessed subjective outcomes. Resolution of watering in outdoor conditions was reported by $84 \%$ of the participants in the external DCR group and $59 \%$ of those in the laser-assisted endonasal DCR group (RR $0.70, \mathrm{Cl} 0.51$ to 0.97 , 64 participants). The subjective success rates were slightly lower than the anatomic success rates. Of the three participants who were considered to be anatomical failures in the external DCR group, two were asymptomatic. This demonstrates that anatomical success does not always correlate with functional success - it has 
been argued (Fayers 2009) that the patient experience is a more meaningful way of evaluating success of DCR than demonstration of patency of the lacrimal system.

There were no cases of intraoperative bleeding in Hartikainen 1998. In the Moras 2011 study (laser-assisted endonasal DCR versus external DCR), $45 \%$ of participants in both groups experienced intraoperative bleeding (RR $1.00,95 \% \mathrm{Cl} 0.50$ to $1.98,40$ participants, 1 study). We judged this evidence on intraoperative bleeding to be very-low certainty, downgrading for risk of bias, imprecision and inconsistency.

There were no postoperative complications in the endonasal group, while two cases of postoperative bleeding (1 requiring readmission) and two cases of wound infection/gaping occurred in the external DCR group.

\section{Overall completeness and applicability of evidence}

The periods of follow-up in the two trials were different (12 months for the first trial and 6 months for the second trial), which presents a difficulty in comparing the data from both trials. Moreover, a sixmonth follow-up period (while being within the limit specified in the protocol) might not uncover some later-onset failures.

In addition to different follow up periods in the two trials, different techniques were also used for endonasal DCR in the two trials. There was also some variability in study design and some difficulty in clarifying the randomisation process in both studies which further limits analysis of data.

\section{Quality of the evidence}

We judged the evidence on anatomic success to be very low-certainty, downgrading for risk of bias, imprecision and inconsistency.

The evidence on complications was also judged to be very-low certainty, downgrading one level for risk of bias and two levels for imprecision, due to the very low number of cases.

The moderate-certainty of the included studies precludes us from drawing any firm conclusions. Endonasal DCR is evolving since its introduction more than a decade ago; as more efficient techniques develop, the success rates for this technique are likely to improve.

\section{Potential biases in the review process}

Several conference proceedings were unavailable for searching and therefore unpublished relevant studies could have been missed.

Future larger RCTs are required to further assess the success and complication rates of endonasal and external DCR. Different techniques of endonasal DCR should also be assessed, as the choice of endonasal technique can influence the outcome. Strict outcome criteria should be adopted to assess functional and anatomical outcomes with a minimal follow-up of six months.

\section{Agreements and disagreements with other studies or reviews}

Huang 2014 reviewed four RCTs and 15 comparative cohort studies. They found that the relative success rates for endonasal mechanical DCR and external DCR were comparable, while success rates for endonasal laser-assisted DCR were lower.
Ben Simon 2005 and Verma 2006 are two non-randomised studies that found a significantly higher rate of success with endonasal mechanical DCR than external DCR (endonasal mechanical DCR was assisted by carbon dioxide laser in Verma 2006).

Cokkeser 2000 and Dolman 2003 are comparative non-randomised studies that obtained comparable success rates between external and endonasal mechanical DCR.

Ibrahim 2001, a retrospective comparative cohort study, found a higher success rate with external DCR than endonasal laser-assisted DCR. (82\% versus $58 \%)$.

\section{AUTHORS' CONCLUSIONS}

\section{Implications for practice}

The success rate for laser-assisted endonasal dacryocystorhinostomy (DCR) was lower than for external DCR, while the success rates for mechanical endonasal and external DCR were similar. We judged the evidence for success to be very low. The differences in effect seen may be due to variations in the endonasal technique, but may also be due to other differences between the trials. Therefore, the relative effects of endonasal and external DCR remain uncertain.

There is clearly a need for robust randomised controlled trials (RCTs) comparing external and endonasal DCR that provide highcertainty evidence which can influence practice.

\section{Implications for research}

More RCTs comparing endonasal and external DCR techniques are required to determine if endonasal DCR provides better results. Double-masking may be difficult due to the external DCR scar, but participants can be masked to the type of procedure, and postoperative evaluation should be by an independent assessor. There is also a need for trials comparing different techniques of endonasal DCR, as the choice of endonasal technique can influence the outcome. Strict outcome criteria should be adopted (Fayers 2009; Moore 2002). Subjective outcome criteria should be assessed based on resolution of patient reported symptoms. Objective outcomes should be based on anatomical success demonstrating lacrimal system patency (syringing of the lacrimal system) or on functional success demonstrated by functional endoscopic dye test or endoscopic inspection of the ostium, and fluorescein dye retention test. Trials that include patient reported outcomes, such as, impact on quality of life or appearance would offer valuable information, especially given the invasive nature of the techniques involved.

\section{ACKNOWLEDGEMENTS}

Cochrane Eyes and Vision created and executed the search strategies. We thank Catey Bunce and Daniel Morris for their comments, and Iris Gordon for her assistance with searches and obtaining articles. We also thank Anupa Shah and Jennifer Evans for author support, and Gianni Virgili for his help with statistical analysis.

We are also grateful to Hsin-wen Wu for translating Chinese reports of trials. 


\section{RE F E R E N C E S}

\section{References to studies included in this review}

Hartikainen 1998 \{published data only (unpublished sought but not used)\}

Hartikainen J, Grenman R, Puukka P, Seppä H. Prospective randomized comparison of external dacryocystorhinostomy and endonasal laser dacryocystorhinostomy. Ophthalmology 1998;105(6):1106-13.

\section{Moras 2011 \{published data only\}}

Moras K, Bhat M, Shreyas CS, Mendonca N, Pinto G. External dacryocystorhinostomy versus endoscopic dacryocystorhinostomy: A comparison. Journal of Clinical and Diagnostic Research 2011;5(2):182-6.

\section{References to studies excluded from this review}

Ajalloueyan 2007 \{published data only\}

Ajalloueyan M, Fartookzadeh M, Parhizgar H. Use of laser for dacrocystorhinostomy. Archives of Otolaryngology - Head \& Neck Surgery 2007;133(4):340-3.

\section{Balikoglu-Yilmaz 2015 \{published data only\}}

Balikoglu-Yilmaz M, Yilmaz T, Taskin U, Taskapili M, Akcay M, Oktay MF, et al. Prospective comparison of 3 dacryocystorhinostomy surgeries: external versus endoscopic versus transcanalicular multidiode laser. Ophthalmic Plastic and Reconstructive Surgery 2015;31(1):13-8.

\section{Derya 2013 \{published data only\}}

Derya K, Demirel S, Orman G, Cumurcu T, Gunduz A. Endoscopic transcanalicular diode laser dacryocystorhinostomy: is it an alternative method to conventional external dacryocystorhinostomy?. Ophthalmic Plastic and Reconstructive Surgery 2013;29(1):15-7.

\section{Hartikainen 1998b \{published data only\}}

Hartikainen J, Antila J, Varpula M, Puukka P, Seppä H, Grénman R. Prospective randomized comparison of endonasal endoscopic dacryocystorhinostomy and external dacryocystorhinostomy. Laryngoscope 1998;108(12):1861-6.

\section{Javate 2010 \{published data only\}}

Javate RM, Pamintuan FG, Cruz RT. Efficacy of endoscopic lacrimal duct recanalization using microendoscope. Ophthalmic Plastic and Reconstructive Surgery 2010;26(5):330-3.

\section{Tang 2015 \{published data only\}}

Tang YZ, Lu HL, Yan SG, Kong XB, Liu XY, Liang KF, et al. Clinical research of the micro-invasive treatments for chronic dacryocystitis with the fifth generation lacrimal endoscope. International Eye Science 2015;15(6):1046-9.

\section{Taskin 2011 \{published data only\}}

Taskin U, Yigit O, Sisman A, Eltutar K, Eryigit T. Comparison of outcomes between endoscopic and external dacryocystorhinostomy with a Griffiths nasal catheter. Journal of Otolaryngology - Head \& Neck Surgery 2011;40(3):216-20.
Yigit 2007 \{published data only\}

Yigit O, Samancioglu M, Taskin U, Ceylan S, Eltutar K, Yener M. External and endoscopic dacryocystorhinostomy in chronic dacryocystitis: Comparison of results. European Archives of OtoRhino-Laryngology 2007;264(8):879-85.

\section{References to studies awaiting assessment}

Cui 2013 \{published data only\}

Cui W, Jiang L, Jiang YH, Xi J. Effects analysis of three kinds of operation methods in treatment of dacryocystitis. International Eye Science 2013;13(7):1510-1.

\section{Zhou 2015 \{published data only\}}

Zhou J, Kong QJ, Li B. Effects comparison of two operation methods in treatment of dacryocystitis. International Eye Science 2015;15(3):565-66.

\section{Additional references}

\section{Atkins 2004}

Atkins D, Best D, Briss PA, Eccles M, Falck-Ytter Y, Flottorp S, et al. GRADE Working Group. Grading quality of evidence and strength of recommendations. BMJ 2004;328(7454):1490.

\section{Bakri 1999}

Bakri SJ, Carney AS, Robinson K, Jones NS, Downes RN. Quality of life outcomes following dacryocystorhinostomy: External and endonasal laser techniques compared. Orbit 1999;18(2):83-8.

\section{Ben Simon 2005}

Ben Simon GJ, Joseph J, Lee S, Schwarcz RM, McCann JD, Goldberg RA. External versus endoscopic dacryocystorhinostomy for acquired nasolacrimal duct obstruction in a tertiary referral centre. Ophthalmology 2005;112(8):1464-8.

\section{Boush 1994}

Boush GA, Lemke BN, Dortzbach RK. Results of endonasal laser assisted dacryocystorhinostomy. Ophthalmology 1994;101(5):955-9.

\section{Caldwell 1893}

Caldwell GW. Two new operations for obstruction of the nasal duct. New York Medical Journal 1893;57:581-2.

\section{Chen 2009}

Chen D, Ge J, Wang L, Gao Q, Ma P, Li N, et al. A simple and evolutional approach proven to recanalise the nasolacrimal duct obstruction. British Journal of Ophthalmology 2009;93(11):1438-43.

\section{Cokkeser 2000}

Cokkeser Y, Evereklioglu C, Er H. Comparative external versus endoscopic dacryocystorhinostomy: Results in 115 patients (130 eyes). Otolaryngology - Head \& Neck Surgery 2000;123(4):488-91. 


\section{Dolman 2003}

Dolman PJ. Comparison of external dacryocystorhinostomy with nonlaser endonasal dacryocystorhinostomy. Ophthalmology 2003;110(1):78-84.

\section{Dupuy-Dutemps 1921}

Dupuy-Dutemps B. Procede plastique de dacryocystorhinostomie et ses resultants. Annales d'Ocullstique 1921;158:241-61.

\section{Fayers 2009}

Fayers T, Laverde T, Tay E, Olver JM. Lacrimal surgery success after external dacryocystorhinostomy: functional and anatomical results using strict outcome criteria. Ophthalmic Plastic and Reconstructive Surgery 2009;25(6):472-5.

\section{Glanville 2006}

Glanville JM, Lefebvre C, Miles JN, Camosso-Stefinovic J. How to identify randomized controlled trials in MEDLINE: ten years on. Journal of the Medical Library Association 2006;94(2):130-6.

\section{GRADEpro GDT 2014 [Computer program]}

GRADE Working Group, McMaster University. GRADEpro GDT. Version accessed 14 September 2016. Hamilton (ON): GRADE Working Group, McMaster University, 2014.

\section{Halle 1914}

Halle M. [Zur intranasalen operation am tranensack]. Archives of Oto-Rhino-Laryngology 1914;28:256-66.

\section{Henson 2007}

Henson RD, Henson RG Jr, Cruz HL Jr, Camara JG. Use of the diode laser with intraoperative mitomycin $\mathrm{C}$ in endocanalicular laser dacryocystorhinostomy. Ophthalmic Plastic and Reconstructive Surgery 2007;23(2):134-7.

\section{Higgins 2011}

Higgins JP, Altman DG, Sterne JAC editor(s). Chapter 8: Assessing risk of bias in included studies. In: Higgins JP, Green S editor(s). Cochrane Handbook for Systematic Reviews of Interventions Version 5.1.0 (updated March 2011). The Cochrane Collaboration, 2011. Available from handbook.cochrane.org.

\section{Hii 2012}

Hii BW, McNab AA, Friebel JD. A Comparison of External and Endonasal Dacryocystorhinostomy in Regard to Patient Satisfaction and Cost. Orbit 2012;31(2):67-76.

\section{Huang 2014}

Huang J, Malek J, Chin D, Snidvongs K, Wilcsek G, Tumuluri K, et al. Systematic review and meta-analysis on outcomes for endoscopic versus external dacryocystorhinostomy. Orbit 2014;33(2):81-90.

\section{Ibrahim 2001}

Ibrahim HA, Batterbury M, Banhegyi G, McGalliard J. Endonasal laser dacryocystorhinostomy and external dacryocystorhinostomy outcome profile in a general ophthalmic service unit: a comparative retrospective study. Ophthalmic Surgery and Lasers 2001;32(3):220-7.

\section{Kennedy 1985}

Kennedy DW. Functional endoscopic sinus surgery technique. Archives of Otolaryngology - Head \& Neck Surgery 1985;111(10):643-9.

\section{Kong 1994}

Kong YT, Kim TI, Kong BW. A report of 131 cases of endoscopic laser lacrimal surgery. Ophthalmology 1994;101(11):1793-800.

\section{Maini 2007}

Maini S, Raghava N, Youngs R, Evans K, Trivedi S, Foy C, et al. Endoscopic endonasal laser versus endonasal surgical dacryocystorhinostomy for epiphora due to nasolacrimal duct obstruction: prospective, randomised, controlled trial. Journal of Laryngology and Otology 2007;121(2):1170-6.

\section{Mathew 2004}

Mathew MR, McGuiness R, Webb LA, Murray SB, Esakowitz L. Patient satisfaction in our initial experience with endonasal endoscopic non-laser dacryocystorhinostomy. Orbit 2004;23(2):77-85.

\section{McDonogh 1989}

McDonogh M, Meiring JH. Endoscopic transnasal dacryocystorhinostomy. Journal of Laryngology and Otology 1989;103(6):585-7.

\section{Metson 1994}

Metson R, Woog JJ, Puliafito CA. Endoscopic laser dacryocystorhinostomy. Laryngoscope 1994;104(3 Pt 1):269-74.

\section{Moore 2002}

Moore WM, Bentley CR, Olver JM. Functional and anatomic results after two types of endoscopic endonasal dacryocystorhinostomy: surgical and holmium laser. Ophthalmology 2002;109(8):1575-82.

\section{Muellner 2000}

Muellner K, Bodner E, Mannor GE, Wolf G, Hofmann T, Luxenberger W. Endolacrimal laser assisted lacrimal surgery. British Journal of Ophthalmology 2000;84(1):16-8.

\section{Ng 2015}

Ng DS, Chan E, Yu DK, Ko ST. Aesthetic assessment in periciliary " $\mathrm{v}$-incision" versus conventional external dacryocystorhinostomy in Asians. Graefe's Archive for Clinical and Experimental Ophthalmology 2015;253(10):1783-90.

\section{Pearlman 1997}

Pearlman SJ, Michalos P, Leib ML, Moazed KT. Translacrimal transnasal laser-assisted dacryocystorhinostomy. Laryngoscope 1997;107(10):1362-5.

\section{Qin 2010}

Qin ZY, Lu ZM, Liang ZJ. Application of mitomycin C in nasal endoscopic dacryocystorhinostomy. International Journal of Ophthalmology 2010;10(8):1569-71. 


\section{Reifler 1993}

Reifler DM. Results of endoscopic KTP laser assisted dacryocystorhinostomy. Ophthalmic Plastic and Reconstructive Surgery 1993;9(4):231-6.

\section{RevMan 2014 [Computer program]}

Nordic Cochrane Centre, The Cochrane Collaboration. Review Manager 5 (RevMan 5). Version 5.3. Copenhagen: Nordic Cochrane Centre, The Cochrane Collaboration, 2014.

\section{Roozitalab 2004}

Roozitalab MH, Amirahmadi M, Namazi MR. Results of the application of intraoperative mitomycin $\mathrm{C}$ in dacryocystorhinostomy. European Journal of Ophthalmology 2004;14(6):461-3.

\section{Saiju 2009}

Saiju R, Morse LJ, Weinberg D, Shrestha MK, Ruit S. Prospective randomized comparison of external dacryocystorhinostomy with and without silicone intubation. British Journal of Ophthalmology 2009;93(9):1220-2.

\section{Seppa 1994}

Seppa H, Grenman R, Hartikainen J. Endonasal CO2-Nd: YAG laser dacryocystorhinostomy. Acta Ophthalmologica 1994;72(6):703-6.

\section{Sham 2000}

Sham CL, van Hasselt CA. Endoscopic terminal dacryocystorhinostomy. Laryngoscope 2000;110(6):1045-9.

\section{Smirnov 2006}

Smirnov G, Tuomilehto H, Terasvirta M, Nuutinen J, Seppa J. Silicone tubing after endoscopic dacryocystorhinostomy: is it necessary?. American Journal of Rhinology 2006;20(6):600-2.

\section{Stammberger 1986}

Stammberger H. Endoscopic endonasal surgery: concepts in treatment of recurring rhinosinusitis. Part II. Surgical technique. Otolaryngology - Head and Neck Surgery 1986;94(2):147-56.

\section{Tarbet 1995}

Tarbet KJ, Custer PL. External dacryocystorhinostomy: surgical success, patient satisfaction and economic cost. Ophthalmology 1995;102(7):1065-70.

\section{Toti 1904}

Toti A. [Nuovo metodo conservatore di cura radicle delle suppurazoni croniche del sacco lacrimale (Dacriocistorinostomia)]. Clinica Moderna Firenze 1904;10:385-7.

\section{Tsirbas 2004}

Tsirbas A, Davis G, Wormald PJ. Mechanical endonasal dacryocystorhinostomy versus external dacryocystorhinostomy. Ophthalmic Plastic and Reconstructive Surgery 2004;20(1):50-6.

\section{Unlu 2009}

Unlu HH, Gunhan K, Baser EF, Songu M. Long term results in endoscopic dacryocystorhinostomy: is intubation really required?. Otolaryngology - Head and Neck Surgery 2009;140(7):589-95.

\section{Verma 2006}

Verma A, Khabori M, Zutshi R. Endonasal carbon-dioxide laser assisted dacryocystorhinostomy verses external dacryocystorhinostomy. Indian Journal of Otolaryngology and Head and Neck Surgery 2006;58(1):9-14.

\section{Watts 2001}

Watts P, Ram AR, Nair R, Williams H. Comparison of external dacryocystorhinostomy and 5-fluorouracil augmented endonasal laser dacryocystorhinostomy. A retrospective review. Indian Journal of Ophthalmology 2001;49(3):169-72.

\section{West 1910}

West JM. A window resection of the nasal duct in cases of stenosis. Transactions of the American Ophthalmological Society 1910;12(Pt 2):654-8.

\section{Woog 1993}

Woog JJ, Metson R, Puliafito CA. Holmium: YAG endonasal laser dacryocystorhinostomy. American Journal of Ophthalmology 1993;116(1):1-10.

\section{Yuce 2013}

Yuce S, Ali A, Dogan M, Uysal IO, Muderris S. Results of Endoscopic Endonasal Dacryocystorhinostomy. Journal of Craniofacial Surgery 2013;24(1):e11-12.

\section{References to other published versions of this review}

\section{Anijeet 2011}

Anijeet D, Dolan L, MacEwen CJ. Endonasal versus external dacryocystorhinostomy for nasolacrimal duct obstruction. Cochrane Database of Systematic Reviews 2011, Issue 1. [DOI: 10.1002/14651858.CD007097.pub2]

\section{Anijeet 2008}

Anijeet D, Dolan L, MacEwen CJ. Endonasal versus external dacryocystorhinostomy for nasolacrimal duct obstruction. Cochrane Database of Systematic Reviews 2008, Issue 2. [DOI: 10.1002/14651858.CD007097]

\section{CHARACTERISTICS OF STUDIES}

Characteristics of included studies [ordered by study ID] 
Hartikainen 1998

\begin{tabular}{|c|c|c|}
\hline Methods & \multicolumn{2}{|c|}{$\begin{array}{l}\text { Randomised controlled trial; simple parallel group design with participants individually randomised to } \\
\text { one of two intervention groups }\end{array}$} \\
\hline Participants & \multicolumn{2}{|l|}{ Country: Finland } \\
\hline & \multicolumn{2}{|c|}{64 eyes (63 participants) } \\
\hline & \multicolumn{2}{|c|}{ Age: range 23 to 89 years } \\
\hline & \multicolumn{2}{|c|}{ Mean age: 65 years } \\
\hline Interventions & \multicolumn{2}{|c|}{$\begin{array}{l}\text { Intervention 1: endonasal laser-assisted dacryocystorhinostomy } \\
\text { Intervention 2: external dacryocystorhinostomy }\end{array}$} \\
\hline Outcomes & \multicolumn{2}{|c|}{ Patent lacrimal passage on irrigation at one year } \\
\hline Notes & \multicolumn{2}{|c|}{ Operations performed between January and December 1994, manuscript received May 1997.} \\
\hline & \multicolumn{2}{|c|}{ Study supported in part by a grant from the Turku University Foundation, Turku, Finland. } \\
\hline & \multicolumn{2}{|c|}{ The authors did not have any proprietary interest in any of the equipment mentioned in the article. } \\
\hline \multicolumn{3}{|l|}{ Risk of bias } \\
\hline Bias & Authors' judgement & Support for judgement \\
\hline $\begin{array}{l}\text { Random sequence genera- } \\
\text { tion (selection bias) }\end{array}$ & Unclear risk & No description of sequence generation is provided in the trial report. \\
\hline $\begin{array}{l}\text { Allocation concealment } \\
\text { (selection bias) }\end{array}$ & Unclear risk & No description of allocation concealment is provided in the trial report. \\
\hline $\begin{array}{l}\text { Blinding (performance } \\
\text { bias and detection bias) } \\
\text { All outcomes }\end{array}$ & Unclear risk & $\begin{array}{l}\text { No description of masking either the participants or outcome assessors is pro- } \\
\text { vided in the trial report. }\end{array}$ \\
\hline $\begin{array}{l}\text { Incomplete outcome data } \\
\text { (attrition bias) } \\
\text { All outcomes }\end{array}$ & Low risk & $\begin{array}{l}\text { At } 12 \text { months follow-up all participants in both groups were assessed for suc- } \\
\text { cess. Complication rates were also determined for the whole study group. } \\
\text { Therefore there was no incomplete data. }\end{array}$ \\
\hline
\end{tabular}

\section{Moras 2011}

Methods Randomised controlled trial; simple parallel group design with participants individually randomised to
one of two intervention groups

\begin{tabular}{ll}
\hline Participants & Country: India \\
& 40 eyes (40 participants) \\
& Age: $16-68$ \\
& Mean age: not specified \\
\hline Interventions & Intervention 1: endonasal mechanical dacryocystorhinostomy using punch forceps \\
\hline Outcomes & Patent lacrimal drainage system on sac syringing at the end of 6 months \\
\hline
\end{tabular}


Moras 2011 (Continued)

Notes

Date of submission: December 2010 (date of study not available from article).

No competing interests declared by authors.

\section{Risk of bias}

\begin{tabular}{|c|c|c|}
\hline Bias & Authors' judgement & Support for judgement \\
\hline $\begin{array}{l}\text { Random sequence genera- } \\
\text { tion (selection bias) }\end{array}$ & Unclear risk & 'They were randomised into two groups' with no further description. \\
\hline $\begin{array}{l}\text { Allocation concealment } \\
\text { (selection bias) }\end{array}$ & Unclear risk & No description of allocation concealment is provided in the trial report. \\
\hline $\begin{array}{l}\text { Blinding (performance } \\
\text { bias and detection bias) } \\
\text { All outcomes }\end{array}$ & Unclear risk & $\begin{array}{l}\text { Masking of surgeons not possible. No description of masking either the partici- } \\
\text { pants or outcome assessors is provided in the trial report. }\end{array}$ \\
\hline $\begin{array}{l}\text { Incomplete outcome data } \\
\text { (attrition bias) } \\
\text { All outcomes }\end{array}$ & Low risk & At 6 months there were no participants lost to follow-up. \\
\hline
\end{tabular}

Characteristics of excluded studies [ordered by study ID]

\begin{tabular}{|c|c|}
\hline Study & Reason for exclusion \\
\hline Ajalloueyan 2007 & $\begin{array}{l}\text { Even though the authors describe their surgery as endonasal, the technique described in the full- } \\
\text { text of the trial is that of transcanalicular rather than endonasal DCR. }\end{array}$ \\
\hline Balikoglu-Yilmaz 2015 & $\begin{array}{l}\text { Prospective study comparing outcomes of external DCR, mechanical endonasal DCR and tran- } \\
\text { scanalicular DCR using multidiode laser. Study excluded as it was non-randomised, the procedure } \\
\text { being chosen according to participant preference. }\end{array}$ \\
\hline Derya 2013 & $\begin{array}{l}\text { The endoscopic procedure involved a transcanalicular approach with the diode laser probe instead } \\
\text { of an endonasal one. }\end{array}$ \\
\hline Hartikainen 1998b & $\begin{array}{l}\text { The same group conducted the two studies: Hartikainen } 1998 \text { and Hartikainen } 1998 \mathrm{~b} \text {. The exter- } \\
\text { nal DCR group in these two studies appear to be the same. We were unsuccessful in our attempts to } \\
\text { contact the authors to clarify this matter. }\end{array}$ \\
\hline Javate 2010 & $\begin{array}{l}\text { This trial uses a lacrimal microendoscope with a trephine to remove fibrous obstruction along the } \\
\text { lacrimal sac and nasolacrimal sac. It does not create an alternative drainage pathway using an en- } \\
\text { donasal technique which is what our review evaluates. }\end{array}$ \\
\hline Tang 2015 & $\begin{array}{l}\text { This study used a transcanalicular approach using a fifth generation lacrimal endoscope with a mi- } \\
\text { crodrill, instead of an endonasal technique. }\end{array}$ \\
\hline Taskin 2011 & Alternate allocation used, therefore this study does not qualify as a randomised controlled trial. \\
\hline Yigit 2007 & The full-text article revealed that the study was not a randomised trial. \\
\hline
\end{tabular}

DCR: dacryocystorhinostomy 
Characteristics of studies awaiting assessment [ordered by study ID]

Cui 2013

\begin{tabular}{ll}
\hline Methods & $\begin{array}{l}\text { Participants randomly divided into } 3 \text { treatment groups; details of randomisation process not avail- } \\
\text { able }\end{array}$ \\
\hline Participants & 182 cases (202 eyes) \\
\hline Interventions & External dacryocystorhinostomy \\
& Endonasal endoscopic dacryocystorhinostomy \\
\hline Outcomes & Criteria for success not defined in abstract \\
\hline Notes & $\begin{array}{l}\text { Only Chinese version of article available. Chinese translator asked by CEV Information Specialist } \\
\text { to contact study authors on June 4th 2015 for additional information about study (methods of ran- } \\
\text { domisation etc). No response from study authors. }\end{array}$ \\
\hline
\end{tabular}

Zhou 2015

\begin{tabular}{ll}
\hline Methods & $\begin{array}{l}\text { Participants randomly divided into } 2 \text { treatment groups. Translation of methods section in full-text } \\
\text { Chinese article is as follows 'The sample is a collection of cases of people with chronic dacryocys- } \\
\text { titis from November } 2010 \text { to January } 2011 \text { within the author's hospital - Songjiang District Central } \\
\text { Hospital. There are } 2 \text { males and } 35 \text { females, aged from } 25 \text { to } 63 \text { years of age (average } 44.03 \pm 7.13) ' . \\
\text { Unable to ascertain method of randomisation from this description. }\end{array}$ \\
\hline Participants & 37 cases (37 eyes) with chronic dacryocystitis \\
\hline Interventions & External dacryocystorhinostomy \\
\hline Outcomes & Endonasal endoscopic dacryocystorhinostomy combined with intubation of lacrimal ducts \\
\hline Criteria of 'success' not defined in abstract \\
Study authors emailed by Chinese translator on 12 Oct 2015 - no response from study authors to \\
date
\end{tabular}

\section{DATA AND ANALYSES}

\section{Comparison 1. Endonasal versus external DCR}

\begin{tabular}{lllll}
\hline $\begin{array}{l}\text { Outcome or subgroup } \\
\text { title }\end{array}$ & No. of studies & $\begin{array}{l}\text { No. of partici- } \\
\text { pants }\end{array}$ & Statistical method & Effect size \\
\hline 1 Anatomic success & 2 & & Risk Ratio (M-H, Fixed, 95\% Cl) & Subtotals only \\
\hline 1.1 Laser-assisted & 1 & 64 & Risk Ratio (M-H, Fixed, 95\% Cl) & $0.69[0.52,0.92]$ \\
\hline 1.2 Mechanical & 1 & 40 & Risk Ratio (M-H, Fixed, 95\% Cl) & $1.0[0.81,1.23]$ \\
\hline
\end{tabular}




\begin{tabular}{lllll}
\hline $\begin{array}{l}\text { Outcome or subgroup } \\
\text { title }\end{array}$ & No. of studies & $\begin{array}{l}\text { No. of partici- } \\
\text { pants }\end{array}$ & Statistical method & Effect size \\
\hline 2 Subjective success & 1 & & Risk Ratio (M-H, Fixed, 95\% Cl) & Totals not selected \\
\hline 3 Intraoperative bleeding & 2 & Risk Ratio (M-H, Fixed, 95\% Cl) & Totals not selected \\
\hline 3.1 Laser-assisted & 1 & Risk Ratio (M-H, Fixed, 95\% Cl) & $0.0[0.0,0.0]$ \\
\hline 3.2 Mechanical & 1 & Risk Ratio (M-H, Fixed, 95\% Cl) & $0.0[0.0,0.0]$ \\
\hline 4 Postoperative bleeding & 2 & Risk Ratio (M-H, Fixed, 95\% Cl) & $0.33[0.04,3.10]$ \\
\hline 4.1 Laser-assisted & 1 & 104 & Risk Ratio (M-H, Fixed, 95\% Cl) & $0.33[0.01,7.89]$ \\
\hline 4.2 Mechanical & 1 & 64 & Risk Ratio (M-H, Fixed, 95\% Cl) & $0.33[0.01,7.72]$ \\
\hline 5 Wound infection/gap- & 2 & Risk Ratio (M-H, Fixed, 95\% Cl) & Totals not selected \\
\hline \begin{tabular}{llll} 
ing \\
\hline 5.1 Laser-assisted
\end{tabular} & 1 & 40 & Risk Ratio (M-H, Fixed, 95\% Cl) & $0.0[0.0,0.0]$ \\
\hline
\end{tabular}

Analysis 1.1. Comparison 1 Endonasal versus external DCR, Outcome 1 Anatomic success.

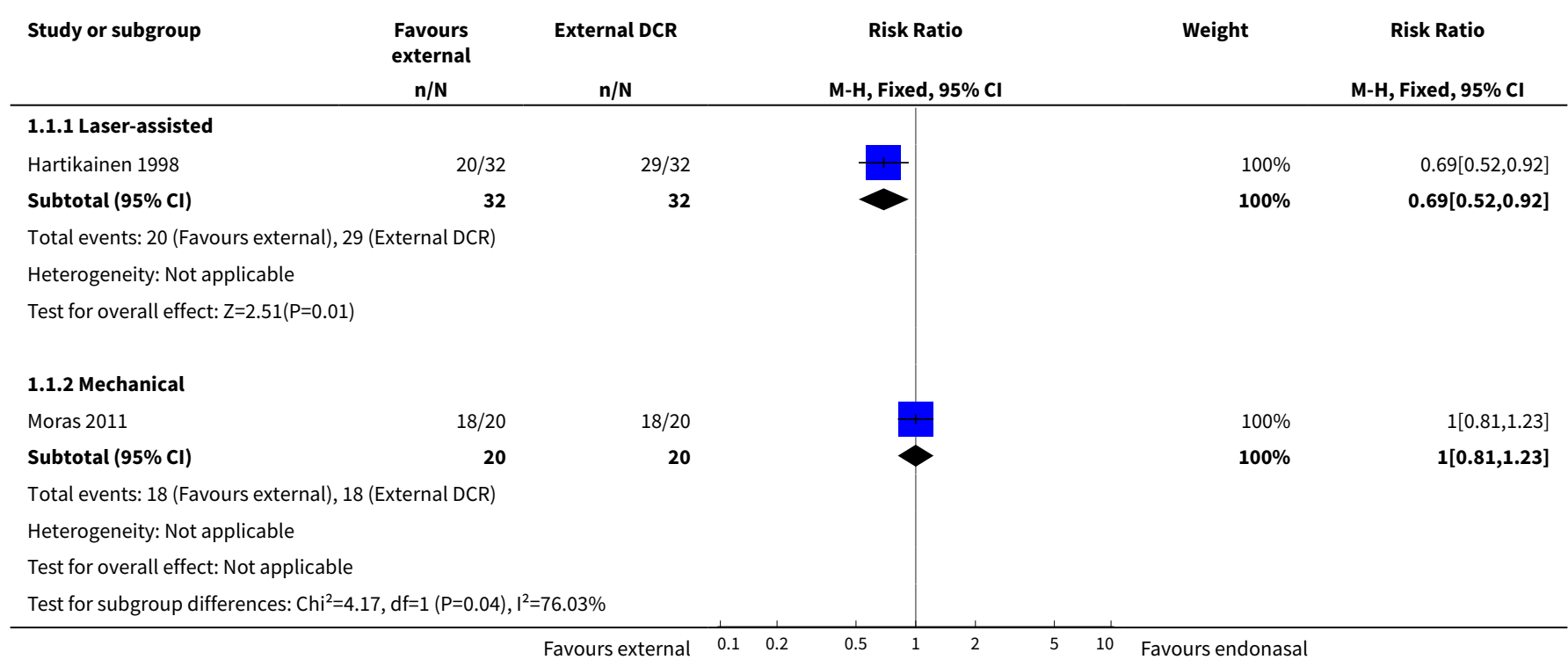

Analysis 1.2. Comparison 1 Endonasal versus external DCR, Outcome 2 Subjective success.

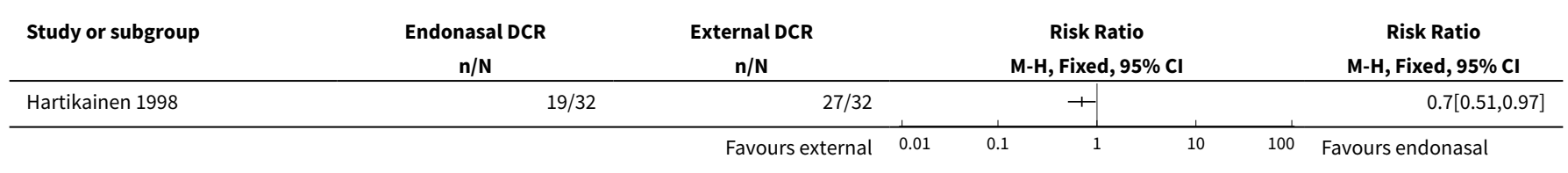




\section{Analysis 1.3. Comparison 1 Endonasal versus external DCR, Outcome 3 Intraoperative bleeding.}

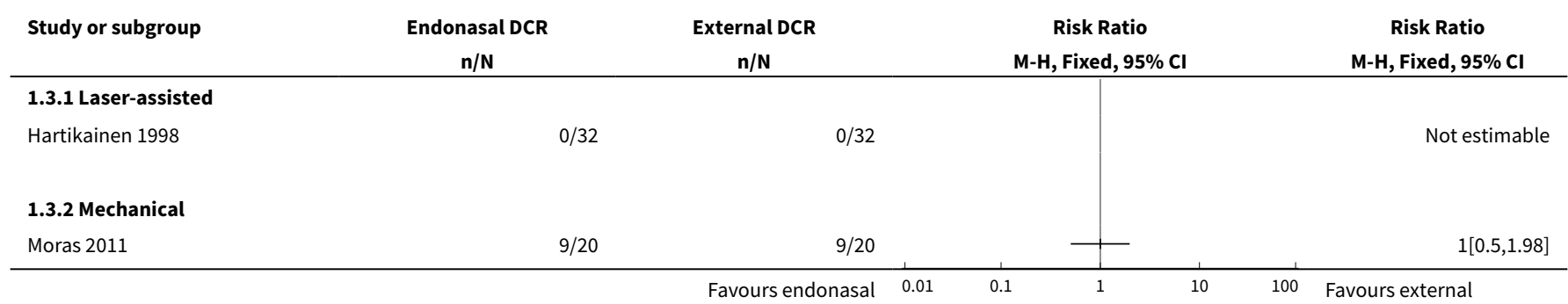

Analysis 1.4. Comparison 1 Endonasal versus external DCR, Outcome 4 Postoperative bleeding.

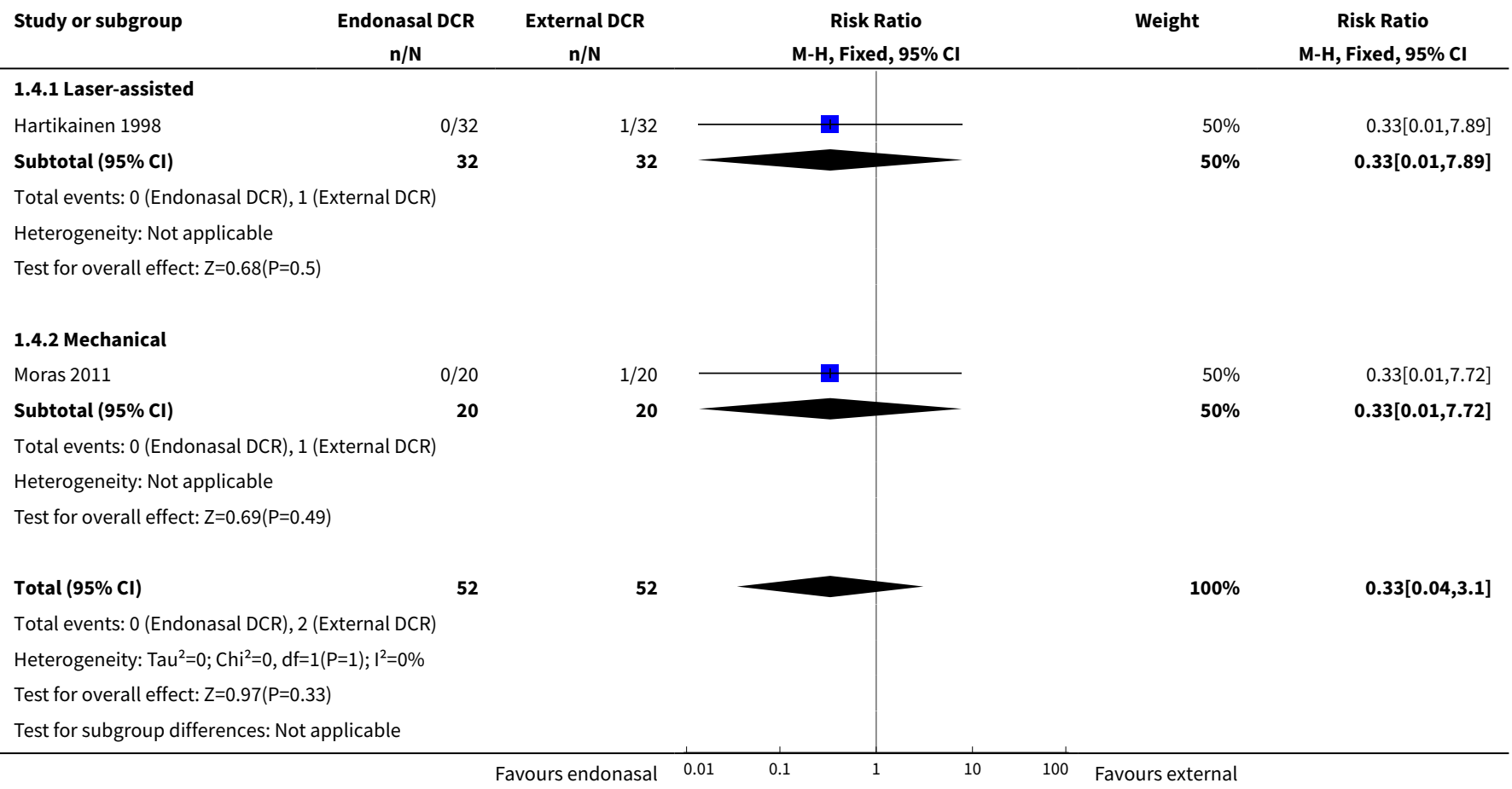

Analysis 1.5. Comparison 1 Endonasal versus external DCR, Outcome 5 Wound infection/gaping.

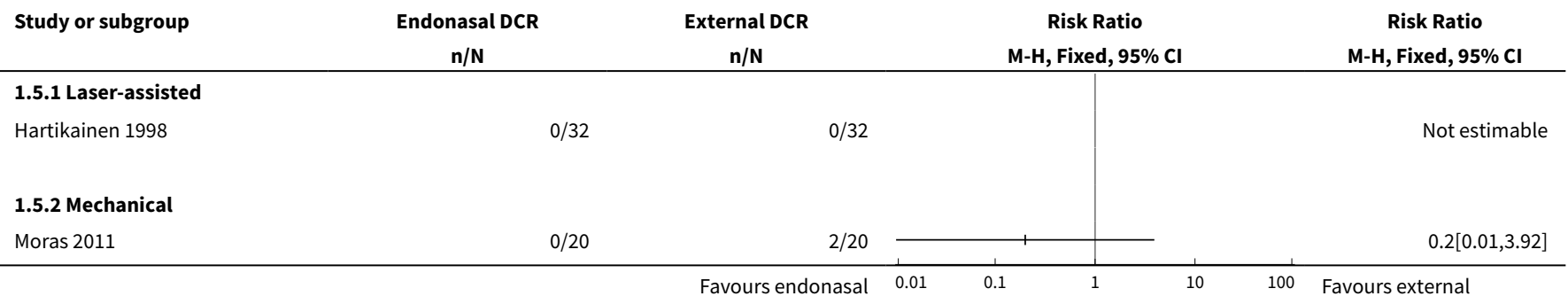




\section{AP PEN DICES}

\section{Appendix 1. CENTRAL search strategy}

\#1 MeSH descriptor: [Dacryocystorhinostomy] explode all trees \#2 dacryocystorhinostom*

\#3 ((endonasal or external or endoscopic or microscopic) near/5 DCR*)

\#4 MeSH descriptor: [Lacrimal Apparatus] explode all trees

\#5 MeSH descriptor: [Lacrimal Apparatus Diseases] this term only \#6 MeSH descriptor: [Lacrimal Duct Obstruction] this term only \#7 MeSH descriptor: [Nasolacrimal Duct] this term only \#8 MeSH descriptor: [Dacryocystitis] this term only

\#9 dacryocystitis

\#10 lacrimal near/4 (obstruct* or block $^{\star}$ )

\#11 nasolacrimal near/4 (obstruct* or block $^{\star}$ )

$\# 12 \# 1$ or $\# 2$ or \#3 or \#4 or \#5 or \#6 or \#7 or \#8 or \#9 or \#10 or \#11

\section{Appendix 2. MEDLINE Ovid search strategy}

1. randomized controlled trial.pt.

2. (randomized or randomised).ab,ti.

3. placebo.ab,ti.

4. dt.fs.

5. randomly.ab,ti.

6. trial.ab,ti.

7. groups.ab,ti.

8. or/1-7

9. exp animals/

10. exp humans/

11.9 not (9 and 10$)$

12. 8 not 11

13. exp dacryocystorhinostomy/

14. dacryocystorhinostom\$.tw.

15. ((endonasal or external or endoscopic or microscopic) adj5 DCR\$).tw.

16. exp Lacrimal Apparatus/

17. Lacrimal Apparatus Diseases/

18. Lacrimal duct obstruction/

19. Nasolacrimal Duct/

20. Dacryocystitis/

21. dacryocystitis.tw.

22. (lacrimal adj4 (obstruct\$ or block\$)).tw.

23. (nasolacrimal adj4 (obstruct\$ or block\$)).tw.

24. or/13-23

25. 12 and 24

The search filter for trials at the beginning of the MEDLINE strategy is from the published paper by Glanville 2006.

\section{Appendix 3. Embase Ovid search strategy}

1. exp randomized controlled trial/

2. exp randomization/

3. exp double blind procedure/

4. exp single blind procedure/

5. random\$.tw.

6. or/1-5

7. (animal or animal experiment).sh.

8. human.sh.

9.7 and 8

10. 7 not 9

11.6 not 10

12. exp clinical trial/

13. (clin\$ adj3 trial\$).tw.

14. ((singl\$ or doubl\$ or trebl\$ or tripl\$) adj3 (blind\$ or mask\$)).tw.

Endonasal versus external dacryocystorhinostomy for nasolacrimal duct obstruction (Review)

Copyright (c) 2017 The Cochrane Collaboration. Published by John Wiley \& Sons, Ltd. 
15. exp placebo/

16. placebo\$.tw.

17. random\$.tw.

18. exp experimental design/

19. exp crossover procedure/

20. exp control group/

21. exp latin square design/

22. or/12-21

23. 22 not 10

24. 23 not 11

25. exp comparative study/

26. exp evaluation/

27. exp prospective study/

28. (control\$ or prospectiv\$ or volunteer\$).tw.

29. or $/ 25-28$

30. 29 not 10

31.30 not ( 11 or 23 )

32. 11 or 24 or 31

33. dacryocystorhinostomy/

34. dacryocystorhinostom\$.tw.

35. ((endonasal or external or endoscopic or microscopic) adj5 DCR\$).tw.

36. lacrimal duct/

37. lacrimal duct occlusion/

38. dacryocystitis/

39. dacryocystitis.tw.

40. (lacrimal adj4 (obstruct\$ or block\$)).tw.

41. (nasolacrimal adj4 (obstruct\$ or block\$)).tw.

42. or/33-41

43. 32 and 42

\section{Appendix 4. LILACS search strategy}

dacryocystorhinostom $\$$ or dacryocystitis or DCR or lacrimal and obstruc\$ or block\$

\section{Appendix 5. Web of Science CPCI-S search strategy}

\#4 \#1 OR \#2 OR \#3

\#3 TS= lacrimal obstruc*

\#2 TS=dacryocystitis

\#1 TS=dacryocystorhinostom*

\section{Appendix 6. ISRCTN search strategy}

dacryocystorhinostomy OR dacryocystitis

\section{Appendix 7. ClinicalTrials.gov search strategy}

Dacryocystorhinostomy OR Dacryocystitis

\section{Appendix 8. WHO ICTRP search strategy}

Dacryocystorhinostomy OR Dacryocystitis

\section{WHAT'S NEW}

\begin{tabular}{lll}
\hline Date & Event & Description \\
\hline 22 August 2016 & $\begin{array}{l}\text { New citation required but conclusions } \\
\text { have not changed }\end{array}$ & $\begin{array}{l}\text { Issue 2 2017: We identified one new trial that fulfilled the inclu- } \\
\text { sion criteria (Moras 2011). }\end{array}$ \\
\hline 22 August 2016 & New search has been performed & Issue 2 2017: We updated the electronic searches. \\
\hline
\end{tabular}




\section{HISTORY}

Protocol first published: Issue 2, 2008

Review first published: Issue 1, 2011

\begin{tabular}{lll}
\hline Date & Event & Description \\
\hline 19 March 2008 & Amended & Converted to new review format. \\
\hline
\end{tabular}

\section{CONTRIBUTIONS OF AUTHORS}

Conceiving the review: Cochrane Eyes and Vision

\section{1 version}

- Designing the review: DA

- Co-ordinating the review: DA

- Data collection for the review

- Designing electronic search strategies: Cochrane Eyes and Vision Group Trials Search Co-ordinator

- Undertaking manual searches: DA

- Screening search results: DA, LD

- Organising retrieval of papers: DA, LD

- Screening retrieved papers against inclusion criteria: DA, LD

- Appraising quality of papers: DA, LD

- Extracting data from papers: DA, LD

- Writing to authors of papers for additional information: DA

- Providing additional data about papers: DA

- Obtaining and screening data on unpublished studies: DA

- Data management for the review:

- Entering data into RevMan: DA, LD

- Analysis of data: DA, LD

- Interpretation of data

- Providing a methodological perspective: DA, CJM

- Providing a clinical perspective: DA, CJM

- Providing a policy perspective: DA, CJM

- Providing a consumer perspective: DA, CJM

- Writing the review: DA, LD, CJM

- Providing general advice on the review: CJM

\section{7 update}

LJ and DA screened the search results, extracted data, assessed studies for bias and wrote to trial investigators for additional information. CJM provided general advice on the review. LJ wrote the text for the update of the review.

\section{DECLARATIONS OF INTEREST}

Lona Jawaheer: none known

Caroline MacEwen: none known

Deepa Anijeet: none known

\section{SOURCES OF SUPPORT}

\section{Internal sources}

- No sources of support supplied 


\section{External sources}

- National Institute for Health Research (NIHR), UK.

- Richard Wormald, Co-ordinating Editor for Cochrane Eyes and Vision (CEV) acknowledges financial support for his CEV research sessions from the Department of Health through the award made by the National Institute for Health Research to Moorfields Eye Hospital National Health Service (NHS) Foundation Trust and UCL Institute of Ophthalmology for a Specialist Biomedical Research Centre for Ophthalmology.

- The NIHR also funds the CEV Editorial Base in London.

The views expressed in this publication are those of the authors and not necessarily those of the NIHR, NHS, or the Department of Health.

\section{DIFFERENCES BETWEEN PROTOCOL AND REVIEW}

We prepared a 'Summary of findings' table and a GRADE assessment which was an amendment to the protocol (Anijeet 2008).

\section{N DEX TERMS}

\section{Medical Subject Headings (MeSH)}

Blood Loss, Surgical; Dacryocystorhinostomy [adverse effects] [ ${ }^{*}$ methods]; Laser Therapy [methods]; Postoperative Hemorrhage [etiology]; Randomized Controlled Trials as Topic; Surgical Wound Infection [etiology]; Treatment Failure

\section{MeSH check words}

Humans 